Article

\title{
Social and Physical Neighbourhood Effects and Crime: Bringing Domains Together Through Collective Efficacy Theory
}

\author{
Sam J. Cole \\ Institute of Criminology, University of Cambridge, Cambridge CB3 9DA, UK; sjc262@cam.ac.uk
}

Received: 31 March 2019; Accepted: 3 May 2019; Published: 10 May 2019

\begin{abstract}
Criminologists and social scientists have long sought to explain why crime rates vary across urban landscapes. By dissecting the city into neighbourhood units, consideration has been given to the comparable features of settings under study which may help to explain why measured crime is higher in certain areas as compared to others. Some, from the socio-spatial perspective, argue that the socio-demographic makeup of a neighbourhood influences the social processes within it relevant to the disruption of crime. Others posit that physical features of neighbourhood settings, which include its layout, architectural design, and more specific measures to 'target harden' buildings against property crimes, can exhibit a deterrent effect. Whilst these explanations profess discrete empirical support, little has been done to consider how these influences may come to explain neighbourhood crime rates concomitantly. In this article, I seek to develop a new socio-physical model in an attempt to integrate and appraise aspects of these domains and their purported ability to explain variations in recorded crime. To achieve this, I use Collective Efficacy theory as a central organising concept which can aid researchers in interrogating current findings. I conclude that the dichotomy between how neighbourhood settings can be both defended, and be defensible, can be addressed by considering the relevance of social cohesion in activating resident social control.
\end{abstract}

Keywords: crime prevention through environmental design; collective efficacy theory; social control; social cohesion; socio-spatial criminology; situational crime prevention; guardianship

\section{Introduction}

The study of neighbourhood effects has made a substantive contribution to the understanding of a range of phenomena across the social sciences (Sampson et al. 2002; Sampson 2012; Brunton-Smith et al. 2013). For criminology, the study of how crime is distributed across urban space-and the reasons for this-has a well-established place within the corpus of the discipline (see Bottoms 2012; Weisburd et al. 2012). By dissecting the city into neighbourhood units, researchers have been able to assess a range of comparable features within settings studied, with the presence of certain neighbourhood characteristics used to describe how and explain why crime is highly concentrated (Sherman et al. 1989; Weisburd et al. 2012; Wikström et al. 2012; Wikström 1991). The trend in recent research of adopting a 'small is better' approach to measure neighbourhood effects (Oberwittler and Wikström 2009; Taylor 2015), with units of aggregation such as street segments (Weisburd et al. 2012), small administrative boundaries, such as UK Census Output Areas (Wikström et al. 2012), and even a focus on individual residential properties within a neighbourhood (Armitage et al. 2010), has allowed researchers to assess these influences with much greater specificity.

Despite a shared focus on the 'neighbourhood' as a unit of analysis, criminologists are divided in the features that they see as most relevant to explaining variations in crime. Some, from the socio-spatial perspective (see Bottoms 2012), focus on the social aspects of settings, with aggregate socio-demographic neighbourhood features said to influence social processes relevant to the facilitation or disruption of 
crime. Others, from the perspective of crime prevention through environmental design (abbreviated to CPTED), analyse how physical features of a setting — such as building and street design—and adaptions which 'target harden' built-form aspects against crime, create a deterrent effect against offending. Studied together, both of these perspectives demonstrate a situational neighbourhood effect on crime (Tseloni et al. 2004; Reynald 2011b; Weisburd et al. 2012). Despite this, little has been done to consider further how these features interact to impact upon the everyday neighbourhood social processes of relevance in explaining experiences of crime (Armitage 2013; Cozens and Love 2015, p. 399; Sampson 2006; Sampson 2016). Many of the purported socio-spatial explanations may be influenced by the ecology of neighbourhood units studied; and physical affordances in neighbourhood design may also depend on the social makeup necessary to foster active citizenry. In this paper, I argue that in order to appraise neighbourhood opportunities for crime both physical and social features of settings should be considered concomitantly.

I begin with a brief theoretical and empirical overview of key contributions to the neighbourhood effects debate within the socio-spatial and CPTED domains. Discussion will then respond to the call for scholars to consider how aspects of these explanatory features can be integrated within criminological study (Armitage 2013; Cozens and Love 2015, p. 399; Sampson 2016; Reynald 2011b) by using Sampson et al.'s (1997) conceptual model of collective efficacy as an organising framework. In doing so, we see that some of the specified mechanisms within domains rely upon yet are contradicted by one another, raising questions about suggested neighbourhood effects. To remedy this, I suggest how future empirical assessments can be configured by using systematic social observations and community survey research data to disentangle current inconsistencies. It is hoped that by doing so, social scientists can better understand and represent neighbourhood effects on crime, continuing the study of crime within place (Weisburd et al. 2012; Wikström et al. 2012; Bottoms 2017; Reynald 2011b).

\section{Social Features of Settings: Socio-Spatial Perspectives and Collective Efficacy}

Socio-spatial criminology has a long-standing history, spawned largely from work of the Chicago School from the 1930s onwards (e.g., Park et al. 1925). The 'social disorganisation' perspective posits that urban crime variation can be explained through the study of neighbourhood residents' social and demographic features. Wikström (2007a) notes that Kornhauser (1978) was one of the first to specify and delineate some of the social processes which connect neighbourhood population features-such as social disadvantage, a high population turnover, and population heterogeneity-with residents' crime involvement. Socially-disorganised neighbourhoods failed to encourage informal social control necessary to tackle neighbourhood delinquency; a churn in resident populations meant social cohesion and shared neighbourhood norms were untenable; and high levels of social disadvantage reduced connections of social capital (Wikström 2007a summary of Kornhauser 1978; see also Bursik 2015). This perspective has influenced the work of what Anthony Bottoms termed the 'neo Chicagoans' (Bottoms 2012), with a resurgence of criminological research connecting neighbourhood social features to 'social-interactional and institutional mechanisms' occurring within them (Sampson et al. 2002). The 'community', therefore, has become a central organising lens through which to study neighbourhood effects on crime today. ${ }^{1}$

Linking community variation with a focus on the prevention, and therefore explanation of, crime, is largely articulated through the concept of social control. Informal expressions of social control by residents serve to prevent the commission of, or opportunity for, crime to occur within a given setting. In other words, the sum of individuals making up a 'community' can shape opportunities for criminal activity within a neighbourhood setting (Wilcox et al. 2018, chp. 7). For instance, Reynald's (2009)

1 In their volume Communities and Crime, Wilcox et al. (2018, p. 2) note the 'conceptual ambiguity that prevails in criminology' regarding the operationalisation and study of communities or neighbourhoods. For an engaging discussion on this, see Wilcox et al. (2018, chp. 9). 
four-stage model of guardianship intensity found that the presence of 'invisible', 'available', 'capable' (available, present, and capable of supervision), and 'intervening' (willing to intervene) guardians in a neighbourhood correlated with the level of police-recorded crime within that setting. As guardianship intensity increased, police-recorded property crimes decreased. Interestingly, the difference between the presence of 'capable' and 'intervening' guardians on crime was non-significant, indicating that the visual presence of residents acted to deter offenders before an active willingness to intervene was required (Reynald 2009, p. 15). Similar supportive findings have also been found in the USA (Hollis-Peel et al. 2012).

Despite individual differences evidenced in guardianship practices (Reynald 2010), an understanding of the social contexts within which social control is formed is key when assessing how a neighbourhood-and so a 'community' of sorts-affects levels of crime. Defined as 'social cohesion among neighbours combined with their willingness to intervene on behalf of the common good', Sampson et al. (1997) developed the concept of collective efficacy (hereinafter, CE) as a community-level social process to link aggregate demographic features to neighbourhood crime rates. For Sampson et al. (1997, p. 918) residents of neighbourhoods are assumed to ascribe to a 'common good' of wishing to live in a safe and orderly environment; however, what ultimately differs is their ability to organise themselves effectively to achieve and enforce this. Thus, in order to exercise social control, residents must be in agreement about the need to intervene and share a common, collective approach to neighbourhood concerns; social cohesion, therefore, acts as a binding source of intervening practices. Where mistrust amongst residents pervades, the willingness of individuals to intervene for the 'common good' decreases, allowing the opportunity for crime to be committed (Sampson et al. 1997, p. 919). In seeking to align social disorganisation perspectives with the 'modern realities of urban life', CE theory begins with the premise that a network of strong, dense neighbourhood social ties does not necessarily protect a locality from criminality (Sampson 2012) ${ }^{2}$. Rather, it is repeated and observable interactions which create shared norms and expectations for the future in a locality (Sampson 2006, p. 39; Sampson 2012, p. 153).

Whilst, by implication, the concept of CE highlights that socially-cohesive communities can achieve effective control over their neighbourhood, the development of these processes is ultimately influenced by aggregate-level neighbourhood characteristics. In line with social disorganisation theories, concentrated disadvantage and high rates of residential mobility reduce social cohesion due to a lack of invested interest in community life (Sampson et al. 1997, p. 919). The tethered financial investment of homeowners encourages a longsighted commitment to the 'commonweal of neighbourhood life' - stabilising and ensuring the necessary time for trust and social cohesion to form (Sampson 2012, p. 154). CE is not immune from the socio-economic context within which communities form (Sampson and Morenoff 2004) nor the imbuement of wider, macro-level factors which come to shape them (Sampson 2004) — it can be a product of them.

The importance of this theory is arguably founded upon how it has been operationalised in community survey research. In 1997, Sampson and colleagues developed a vignette survey measure of neighbourhood social cohesion and trust ${ }^{3}$, and neighbourhood social control ${ }^{4}$ (Raudenbush and Sampson 1999). From interviews with 8782 residents across 343 Chicago neighbourhoods, a summary measure of their neighbourhood CE score was formed by combining both measures of social cohesion and social control $(r=0.80, p<0.001)$ (Sampson et al. 1997, p. 920). From survey measures of perceived neighbourhood violence and self-reported violent victimisation, along with police-recorded

2 Dense social ties are not always prosocial in nature. See Sampson (2012, p. 151).

3 Respondents were asked the extent to which 'this is a close-knit neighbourhood', 'people in this neighbourhood can be trusted', 'are willing to help their neighbors', 'share the same values', and conversely 'generally don't get along' (reverse coded).

4 Respondents were further asked to assess the likelihood that their neighbours would intervene if 'children were skipping school', 'showing disrespect to an adult', 'spray painting graffiti' 'a fight broke out in front of their home' and the 'fire station was threatened with budget cuts'. 
rates of homicide, their findings revealed that as neighbourhood levels of CE increased, the rate of violent crime effectively decreased ${ }^{5}$. Alongside domestic replications providing empirical support (Duncan et al. 2003; Morenoff et al. 2001; Sampson et al. 1999; Browning 2002; Morenoff et al. 2001; Browning et al. 2004; Maimon and Browning 2010; Sampson 2012, pp. 149-78), Sampson and Wikström (2008) directly compared the explanatory power of CE in Chicago to the Swedish capital of Stockholm. They found that both cities differed significantly in their respective levels of violence and social disadvantage; yet, social cohesion and social control were similarly highly correlated in Stockholm as they were in Chicago (Sampson and Wikström 2008, p. 104). Furthermore, there was a 'clear negative association, linear in pattern, and similar in slope' between CE and both self-reported and police-recorded violent crimes-despite Chicago's substantially higher overall counts (Sampson and Wikström 2008, p. 112). Further international studies in Brisbane, Australia (Mazerolle et al. 2010) and Peterborough, United Kingdom (Wikström et al. 2012) confirm this trend.

Despite recurrent empirical support, the strength of CE as an explanatory mechanism decreases when aggregating to smaller neighbourhood units. Studies drawn from the project on human development in Chicago neighborhoods aggregated data to units of around 8000 residents. Reducing the scale to 1500 residents, Sutherland et al. (2013) found CE to be 'considerably weaker' in explaining decreases in crime across London, UK. Social explanations for such disparities have considered the level of agreement_-or rather, disagreement-amongst respondents within the same neighbourhood regarding perceptions of social cohesion and social control (Brunton-Smith et al. 2018; Oberwittler and Wikström 2009; Hipp et al. 2018). Taking the 'small is better approach' further, we see that the relevance of physical features within settings can also shape how CE operates on the ground. When aggregating to UK Census Output Areas-which average 300 residents-Wikström et al. (2012) found that non-residential land use, rather than $\mathrm{CE}$, was the strongest predictor of police-recorded crime counts across Peterborough, $\mathrm{UK}^{6}$. By breaking down neighbourhoods to take account of local commercial centres, we see that factors such as the nature of businesses within them (Weisburd et al. 2012) and visitors to settings (Brantingham and Brantingham 1993; Brantingham et al. 2018) are of more relevance to this 'neighbourhood' than residents' cohesive interactions. Even within units of high CE, Wikström et al. (2012) found that parks were popular settings for young people's self-reported crime. Thus, whilst socio-spatial explanations make an impactful contribution to understanding the variation of crime by place, there is need to consider how social processes interact with the features of settings to shape such outcomes. Decreases in scale reveal further nuance to social process pathways (Weisburd et al. 2015).

\section{Physical Features of Settings-The Broad Catchment of Crime Prevention Through Environmental Design (CPTED)}

Whilst socio-demographic features are mediated by CE (population turnover, consequential heterogeneity, social disadvantage) consideration of how physical features of neighbourhoods, and purposeful adaptions to these, also influence social processes necessary to tackle crime have not been integrated into socio-spatial study. Criminological research focussing on the physicality of settings was developed to counter the dominance of social disorganisation perspectives (Jeffery 1971). Today, the influence of physical, built-form features on crime is drawn within the discipline of CPTED—meaning Crime Prevention Through Environmental Design. This broad theoretical catchment incorporates an assortment of ecological crime theories which assert that crime is inhibited or permitted (afforded opportunities) by features of the physical environment (Cozens and Love 2015). Armitage (2018) identifies core elements of CPTED research, which seeks to: (i) encourage defensible space and territoriality; (ii) limit the through-movement of people; (iii) enhance surveillance; (iv) enhance physical

5 A two standard deviation increase in CE was associated with a 30\% reduction in self-reported violent victimisation, and a $39.7 \%$ reduction in police-recorded homicide (Sampson et al. 1997, p. 922).

6 CE was the second strongest predictor. 
security; and (v) maintain neighbourhood space. Despite a sizeable body of empirical research across these categories, some criminologists assert that the true effect of CPTED on crime is underspecified and therefore 'poorly tested' (Armitage 2013; Minnery and Lim 2005; Hillier and Shu 2000; Taylor 2002). This is due to a lack of theoretical clarity regarding CPTED principles and scope (Armitage 2013; Ekblom 2011; Reynald and Mihinjac 2019) and the dominance of cross-sectional research designs (Taylor 2002). Whilst criticisms of the domain are important to note, when disentangling aspects of this theoretical catchment there is evidence to suggest that physical characteristics of settings are worthy of consideration alongside social aspects in the micro-level explanation of crime (Tseloni et al. 2004; Reynald 2011b). I submit however that these pathways can only be understood by recognising how these domains may interact to explain crime concomitantly.

Empirically, CPTED has been most successful at explaining variance in property crimes. Target hardening approaches involve designing built-in protections to inhibit the ability of offenders to commit crime successfully (Reynald and Mihinjac 2019) ${ }^{7}$. For example, the use of physical home security measures such as external lights on a sensor and enhanced window locks has been shown to affect trends in burglary rates (Tseloni et al. 2017; Tilley et al. 2015). Research assessments—correlating coded observations of certain design features with measures of neighbourhood crime, and through interviews with persistent offenders - further suggest features such as street design and limiting the consequential through-movement of people (Armitage et al. 2010; Johnson and Bowers 2010), and the presence of a front garden (Montoya et al. 2016) ${ }^{8}$ to account for neighbourhood property crimes. Packages of recommended design specifications have gathered force in the policy sphere, with the secured by design (SBD) scheme promoted by police forces across England and Wales certifying the design of residential homes (Secured By Design 2019), commercial properties (Secured By Design 2015) and even public transport infrastructure (Secured By Design 2014) as hardened against crime. A systematic review of CPTED-type adaptions to settings in the UK and the USA, which blocked street segments to reduce permeability of the setting, reported some short-term 'desirable effects' reducing crime (Welsh and Farrington 2009, p. 101). The extent of adaptions to property, residences, and neighbourhoods, can produce long-term crime reduction benefits is questionable without continuous renewal and re-adaption. In their longitudinal assessment of the effectiveness of SBD over 10 years, Armitage and Monchuk (2011) achieved mixed findings when comparing SBD-certified estates with non-SBD counterparts in Leeds, UK. Whilst SBD estates had experienced substantially lower burglary counts over 10 years, increases and decreases in crime were also evidenced in matched-pair control sites, with differences in victimisation failing to reach statistical significance (Armitage and Monchuk 2011, p. 339). Such differences were therefore said to 'raise concerns regarding the scheme's lifecycle' (Armitage and Monchuk 2011, p. 339) ${ }^{9}$. Thus, whilst CPTED approaches may help explain reductions in property crime, they are limited in accounting for long-term neighbourhood effects.

CPTED's broader influence on crime is also found in work considering how features of urban design can serve to enhance or inhibit acts of social control—necessary, as we have seen, to interrupt the commission of or opportunity for crime within a setting (Sampson et al. 1997). The influence of planned architectural designs has long been theorised by architects and civic planners to shape social interactions amongst patrons (see Rosenau 1959). Research from Newman (1972) and Alice Coleman's department (1990) sought to articulate this link by focussing on the features of specific housing 'projects' or housing

7 Reynald and Mihinjac (2019) note that 'target hardening' forms part of CPTED and Situational Crime Prevention approaches, as per Cornish and Clarke's (2003, p. 90) twenty-five techniques of situational prevention. Whilst SCP is not fully considered here, aspects of the Socio-Physical Model outlined below could be configured to assess interactions between 'target hardening', 'extended guardianship', and 'natural surveillance.'

8 Dependent upon the upkeep and scale of garden shrubbery (see Nee and Taylor 2000).

9 Relatedly, reductions in crimes such as burglary and motor vehicle theft, noted across the U.S., England and Wales, and Australia, have been connected to the improvement in securing such items since the 1990s (Farrell et al. 2014). Yet despite car immobilisers having done just that (Home Office 2016), a recently reported 'five-fold increase' of car theft in the West Midlands region of the UK indicates that offenders may be using recently-developed technology to bypass product adaptions (West Midlands Police and Crime Commissioner 2018). 
'estates' in the USA and UK respectively. At the time, neighbourhoods with high concentrations of social housing experienced a disproportionate amount of crime (Baldwin et al. 1976) ${ }^{10}$; their distinctive 'utopian' designs (Tuffrey 2013) therefore became the focus of explaining social ills. For Newman (1972, p. 78) and others (see Jephcott 1971) the high-rise nature of housing projects limited opportunities for residents to engage in 'natural surveillance' of their neighbourhoods. The design of such 'projects' promoted blurred boundaries between public and private space, meaning offenders were not challenged by neighbourhood residents. Features seeking to encourage such conditions were set out in Newman's (1976) guidance on creating 'defensible space', which he defined as 'a residential environment whose physical characteristics-building layout and site plan-function to allow inhabitants themselves to become key agents in ensuring their safety'. Similarly, Coleman et al.'s (1990) theoretical and empirical assessment of a housing estate in London, UK, considered how distinct property features-such as the number of dwellings accessible from long internal corridors-meant residents were unable to acknowledge 'legitimate' users of space. Consequently, physical alterations were recommended, reducing the number of residences (so doors) connecting onto corridors, and splitting existing structures effectively in half, suggested to reduce the opportunity for unimpeded offending (Coleman et al. 1990; Coleman 1989, p. 123). Relatedly, resident territoriality may be enhanced by manipulating neighbourhood designs which (i) limit access to the neighbourhood itself; and (ii) permit residents an uninterrupted view of the streetscape. By way of example, the traditional 'true' closed cul-de-sac design-with one route in and street-facing properties-experience significantly less property crime than those with alternative exits (Armitage 2006; Armitage et al. 2010).

Despite empirical associations, understanding the influence of defensible space and territoriality on crime requires further causal unpacking. We see that 'more permeability' is consistently said to lead to 'more crime' (Taylor 2002), and so limiting the access of individuals through design may reduce the opportunities for offending. But to say that such adaptions can then enhance resident social control (see Fennelly and Timothy 2013) requires consideration of distinct analytical social processes. Running through many such narratives is an implicit assumption that affordances ${ }^{11}$ made in building design directly encourage the willingness of residents to intervene and prevent crime. Early criticism of defensible space recognised social dynamics were far more nuanced than Newman's empirical comparisons - conducted between two housing projects with different design features—could consider $^{12}$. Macro-level factors such as residential social and self-selection (Bottoms 1974) and limited knowledge of the micro-level social processes which induce residents to intervene (Merry 1981), were said to compound methodologies employed. Recent calls from writers such as Reynald and Mihinjac (2019) and Reynald (2011b) assert that contributions in the CPTED domain should also be reconciled with research on capable guardians, given the reliance each theoretical catchment has on the other in delineating socially-intervening processes. But as discussed, socio-spatial research asserts the importance of neighbourhood social cohesion as a necessary ingredient to enhance residents' willingness to engage in social control (Sampson et al. 1997). Thus, the effectiveness of defensible space is subject to agreed norms of behaviour and a shared responsibility over it (Wikström et al. 2012).

In light of this, the refined 'Second-generation CPTED' moots the importance of the social dimension of settings as relevant to the sustained influence of CPTED design principles (Cozens and Love 2015, p. 397). 'CPTED2' promotes the integration of social cohesion-such as willingness of residents to observe space and engage in social control-as key elements in activating the affordances made in designing 'defensible' urban space (Cozens et al. 2005; Cozens and Love 2015; Saville and

10 In their study of social housing estates in Sheffield, UK, researchers found that rates of delinquency were not associated with traditional mechanisms of social disorganisation, such as the transience of populations housed.

11 Such as encouraging private space, enhancing lines of sight on to the streetscape (Newman 1972).

12 Whilst Newman adapted his original work to consider propose an optimum balance of 'physical design and social mix' (see Newman 1980), little consideration was given to impact such formulations would have on crime; this was rather assumed owing to the fact residents would be segregated by lifestyles. 
Cleveland 2008). As such, any architectural endeavour which seeks to design-in community needs to factor in programmes which promote the social sustainability of locales (Colquhoun 2004, chp. 5). Whilst this integration is theoretically recognised, little empirical research has been conducted to illustrate the effectiveness of architecturally-infused community cohesion initiatives on neighbourhood crime rates (Cozens and Love 2015, p. 405). Further specification is needed.

\section{Exploring Socio-Spatial and Built-Form Neighbourhood Effects on Crime through Collective Efficacy-A Socio-Physical Model}

On the face of it, the broadening of CPTED principles to account for the relevance of social cohesion appears logical, for its conceptual influence on crime has been well documented. However, in doing so, there is a threat that CPTED expands to contain so many features of potential relevance, that understanding its true effect on crime becomes compounded by and indivisible from social features of settings (Armitage 2013). Furthermore, explaining correlations between features of urban design with neighbourhood levels of crime through their impact upon neighbourhood social processes requires a suitable mechanism of resident action; yet despite expansion through CPTED 2 models, influence in motivating social processes continues to be 'assumed' (Minnery and Lim 2005, p. 331; Ekblom 2019). Reynald's (2011b) mixed-method study of 2847 properties over 94 neighbourhoods in The Hague, Netherlands, is one of the few studies to consider the proportionate explanatory power measured physical and social features of settings have on neighbourhood property crimes and guardianship intensity. With measures operationalising CPTED—such a territoriality, image/maintenance, surveillance opportunities, and target hardening-alongside those of social cohesion, social interactions, and demographic measures of neighbourhood settings, Reynald concludes "that all these factors interact to create conditions that are either ripe with opportunities for capable guardianship or ripe with opportunities for criminal violations" (Reynald 2011b, pp. 135-36). Whilst both socio-physical and socio-demographic measures accounted for $20 \%$ of the variance in observed guardianship intensity, resident surveillance opportunities and distance of properties to the city centre served to explain most of this finding. Many of these explanatory variables were however observed to be highly correlated (Reynald 2011b, p. 133). As shall be discussed, bringing these research silos together requires further analytical consideration.

In order to achieve this analytical clarity, I develop a socio-physical approach, using research findings from both domains in order to specify the potential pathways of influence social and physical features of setting may have on neighbourhood crime rates. My socio-physical model, outlined in Figure 1, hopes to help researchers to disentangle some of these purported links and aid empirical study of the proportionate influence of these neighbourhood features concomitantly. To illustrate the explanatory potential of such an approach, I take aspects of the CPTED cannon-namely defensible space and territoriality, limiting through movement, enhanced surveillance and physical security 'target hardening' techniques-and integrate these findings with the processes delineated by CE research. $\mathrm{CE}$, as distinct from guardianship, provides researchers with an organising conceptual model through which to both connect and disentangle competing or contradictory aspects of the CPTED cannon, for it subsumes the related concepts of social cohesion and social control to form an explanatory mechanism intervening in, or effectively deterring, offending at the neighbourhood level. Appraising how certain design features can shape neighbourhood social cohesion as a further means of enhancing social control, alongside direct influences on social control, may provide a more nuanced understanding of socio-physical neighbourhood effects. 


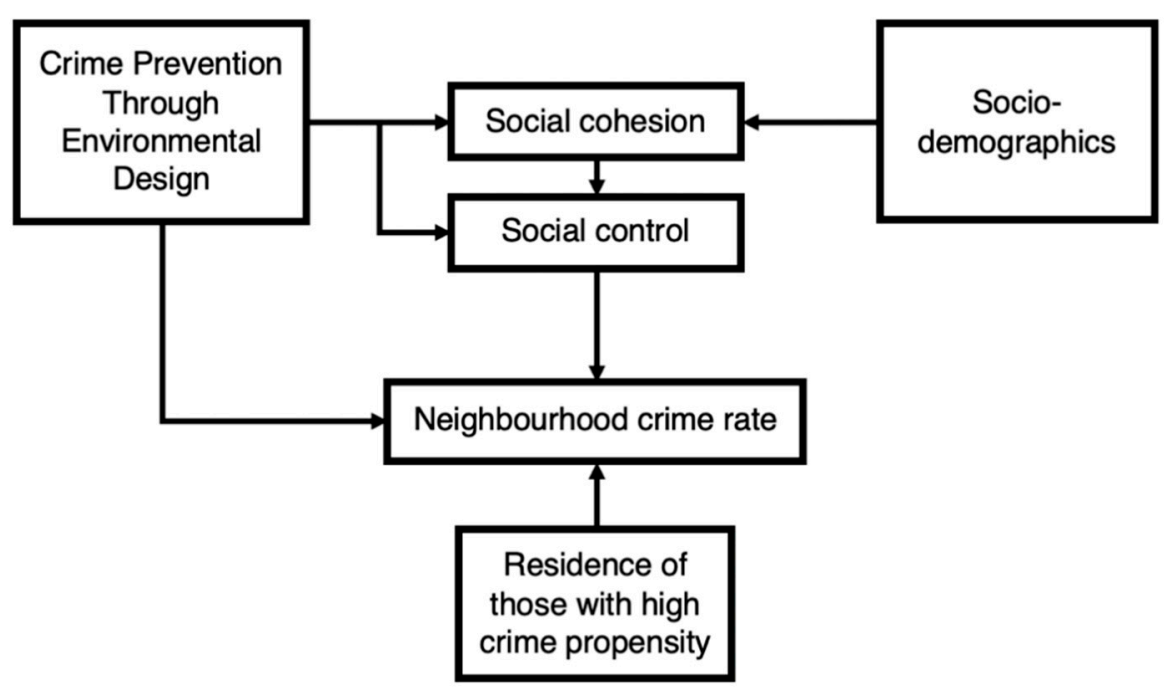

Figure 1. A pathway model illustrating the potential dual influence of physical and social features of neighbourhoods on crime. Potential pathways of influence are deduced from theoretical and empirical research findings to be discussed below, revealing the need for greater specificity of purported influences.

Each aspect of the socio-physical model can be operationalised and expanded upon for empirical study. CE data (measures of social cohesion and social control) can be obtained through community surveys which tap into the social processes operating within neighbourhoods studied (Raudenbush and Sampson 1999; Wikström et al. 2012). Neighbourhood composition can be obtained via large-scale mandated data collection exercises, such as the UK Census. Measures of physical features relevant to a field of study - defensible space, territoriality etc.—via systematic social observations (Raudenbush and Sampson 1999; Reynald 2009, 2011b), with a developed CPTED scale to record frequency of features observed in neighbourhood settings (see examples from Minnery and Lim 2005; Armitage et al. 2010; Abdullah et al. 2013; Reynald 2011b). In this regard, Google Streetview has been validated as a suitable method for researchers to conduct widespread systematic social observations across cities recorded, but only when assessing dormant physical features of environments (Vandeviver 2014; Odgers et al. 2012). This model is therefore applicable to the measurement of neighbourhood effects in pre-existing settings. The temporality of CPTED seeking to design spaces preventively becomes irrelevant; what matters is which physical features directly or indirectly influence crime when organised alongside socio-demographic determinants of neighbourhood social control.

In proposing such a model, I submit some caveats. The pathways outlined in Figure 1 are a crude demonstration of the potential interactions CPTED elements may have on crime-either directly or indirectly through CE. Given that CPTED principles are often promoted as a package, for the sake of analytical and illustrative clarity, I limit my discussion to those aspects outlined above. Whilst not discussed, consideration of how 'activity support' and 'image maintenance' shape CE are also worthy of future integration, especially in light of findings which link disorder to crime through CE (Sampson and Raudenbush 2001) ${ }^{13}$. Furthermore, this model is not what authors refer to as a 'grand theory' explaining all crime and types of offending (Wikström 2017). Theories of action, such as Situational Action Theory (Wikström et al. 2012; Wikström 2017), submit that crime is the product of a person and environment interaction. This Socio-Physical Model should be viewed as an attempt to reconcile contributions which represent neighbourhood units as a potential site of offending. It does not seek to consider how neighbourhood effects shape individual propensity to offend within the context of

13 This is excluded here given that the link between neighbourhood disorder and crime is contested and complex, with many contemporary contributions discrediting broken windows theory. See Sampson and Raudenbush (2001) and Innes (2004), alongside comparisons of Sennett (1996) and Jacobs (1961). 
socialisation and individual development (see Wikström and Sampson 2003; Wikström 2011). This would require the appraisal of very different research questions.

The following section breaks down Figure 1 and considers social and physical situational influences on crime in further detail.

\subsection{Social Features}

\subsubsection{Demographics}

Social-demographic features of neighbourhoods influence the level of social cohesion within that neighbourhood. As has been identified, high levels of social disadvantage, population turnover, and population heterogeneity, have been empirically demonstrated to reduce the extent residents get along and interact to build shared common norms (Sampson 2012; Wikström et al. 2012; Wikström and Sampson 2003). Reduced social cohesion limits resident social control-be that informal, or through the mobilisation of more formal resources (Sampson 2008). Some scholars note that increases in social cohesion may not result in an enhanced willingness to intervene, given that empirical assessments tap into an expectation of action (Steenbeek and Hipp 2011; Wikström 2007b). A number of field experiments using lost letters as a proxy to test such perceptions support the notion that collective expectations of behaviour matter in shaping other-regarding behaviours (Sampson 2012; Volker et al. 2016). Thus, evidence continues to suggest that the social neighbourhood effect on crime can be explained through the process of collective efficacy (Figure 2).

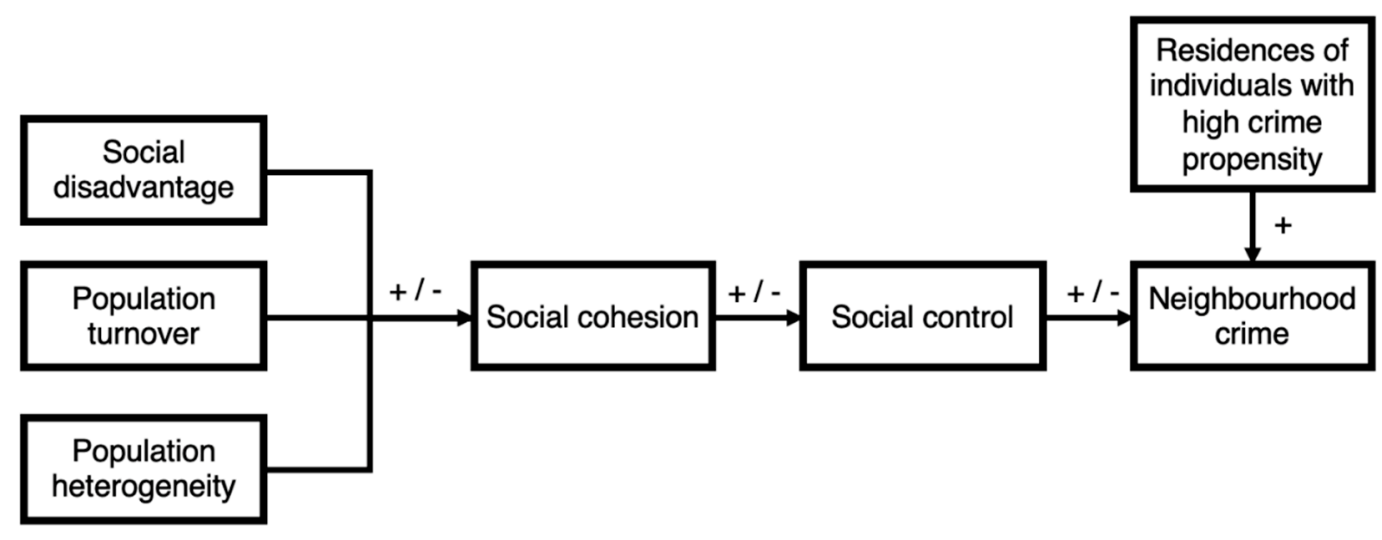

Figure 2. Pathway model illustrating purported socio-demographic influences on crime through CE. Symbols denote an increase or decrease along pathways.

\subsubsection{The Residence and Presence of Frequent Offenders and Those with a High Crime Propensity}

According to CE theory, social control is exercised by residents when they are called upon to act; but as Sampson (2006, p. 40) himself submits that "if high collective efficacy leads to low crime, then at any given moment no intervention will be observed precisely because of the lack of need". The question as to how would-be offenders can discern the level of CE within a setting, and therefore be effectively deterred, is largely assumed (Wikström 2007b). Thus, the effectiveness of direct, or at least the threat of, social control, reduces situational opportunities for crime only if it exerts a sufficient deterrent effect. Persistent offenders are more likely to commit offences in areas in which they already reside (Bernasco 2010; Baldwin et al. 1976); their 'awareness' of that space, and the opportunity that setting provides for offending, can derive from their familiarity with it (Brantingham and Brantingham 1981; Brantingham et al. 2018). Situational action theory indicates that rather than a notion of persistent offenders, criminologists should consider how individuals with a high crime propensity' - low levels of law-relevant morality blurring the distinction between what is right or wrong to do, and an inability to exercise self-control in response to a motivation to offend-interact with the $C E$ of a setting. For such individuals, their deterrence sensitivity may be formed through 
previous 'deterrence experiences', where sanctions inform knowledge about the requisite level of CE within a neighbourhood, consequently affecting the perception of viable action alternatives within that setting (Wikström 2006, p. 356; Wikström 2007b; Wikström et al. 2011, p. 405). Conversely, a lack of having experienced or witnessed social control in an area of low CE may stand to support 'moral habits ${ }^{14}$ - that is, habitual offending, where deliberations about the threat of deterrence are not duly considered (Wikström 2006, p. 103) ${ }^{15}$. Consideration should not only be given to the demographic context of neighbourhood units studied, but also the proximity and activity patterns of those with a high crime propensity.

\subsection{Physical Features}

\subsubsection{Target Hardening}

Target hardening measures may have both a direct and an indirect effect on neighbourhood crime rates (Reynald and Mihinjac 2019). Direct effects namely occur in explaining property crimes, with, for example, home protection security devices and enforced windows and doors limiting the victimisation of such properties (Tseloni et al. 2017; Vollaard and van Ours 2011). The variance in (property) crime at the neighbourhood level is therefore explained as properties become harder to break in to, limiting opportunities for offending in a given context (Figure 3).

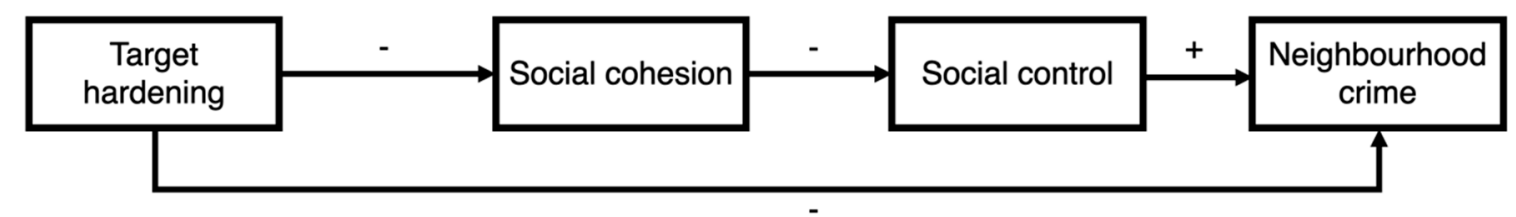

Figure 3. Pathway model illustrating the purported influence of target hardening measures on crime directly and through CE.

Indirect influences may further occur by considering how the differing presentations of these controls—both the social and the physical—can cumulatively shape crime (burglary rates, as typically studied) within a neighbourhood unit (Wilcox et al. 2003; Miethe and Meier 1990). Residents who are concerned and alert to crime are more likely to use target hardening devices in their properties (Minnery and Lim 2005, p. 337) which seemingly complicates our ability to distinguish between effects. Wilcox et al. (2007) considered the interaction between individual-level measures of guardianship (self-reported individual measures of target hardening, home occupancy, informal social control, and defensible space ${ }^{16}$ ) and neighbourhood-level measures (mean scores of individual-level measures at US Census tract level). Through hierarchical logistic modelling (HLM), researchers found that individual-level target hardening was more effective at reducing burglary victimisation where neighbourhood-level target hardening was also high (Wilcox et al. 2007). The deterrent effect of measured target hardening (physical) was enhanced when neighbourhood social guardianship levels increased ${ }^{17}$. Researchers concluded that whilst 'informal social control is still key ... environmental design is assumed to foster/impede such efforts'. Impediments to processes of social control may however come from target hardening measures themselves. For instance, defensive adaptions to properties, such as the presence of window shutters (Cozens and Davies 2013), and high boundary

14 For a summary, see Wikström et al. (2012, pp. 19-22).

15 The importance of considering individuals within settings has been identified in recent reformations of SCP principles, lessening the reliance on rational choice and calculated deterrence mechanisms (Wortley and Tilley 2018).

16 These aspects of guardianship were measured using an index sum of characteristics that interviewed respondents reported as having on their properties. For example, measures of 'target hardening' asked if respondents had engaged in ( 2 years prior) safety precautions including locking doors, leaving lights on when not at home, using a burglar alarm, and keeping a weapon in the home. For full list of items, see Wilcox et al. (2007, p. 782).

17 Measured by the willingness of neighbours to watch over property when individual residents were away. 
fences (Reynald 2011a) have been found to reduce neighbourhood guardianship practices. Thus, whilst measures to target harden may reduce individual victimisation of property offences, the consequential impact is that residents fail to be effective guardians of the neighbourhood outside the property window (Reynald 2009, 2011a, 2011b).

Given the contradiction of effects outlined above, pursuing empirical study organised through CE theory further reminds us of the importance of social cohesion in shaping practices of neighbourhood social control. Do we see, for instance, that the presence of defensive adaptions to neighbourhood properties-'keep out' signs, high fences, gated residences-impacts upon the ability of neighbours to interact within the neighbourhood setting itself? Many writers promote the use of mixed situational, social, and developmental crime prevention strategies (Bottoms 1990; Wikström and Treiber 2017a). Thus, increased securitisation of properties should be configured with an assessment of its impact upon social cohesion (Hope and Karstedt 2003; Garland 2002).

\subsubsection{Neighbourhood Design: Defensible Space, Territoriality, and Enhanced Surveillance}

As stated, the influence of defensible space and street design in explaining neighbourhood crime rates is currently underspecified (Minnery and Lim 2005). When integrating these effects alongside social processes within the setting-here chosen, collective efficacy-a number of potential pathways are revealed: (i) that physical features of neighbourhoods influence the ability of residents to exercise social control effectively; (ii) that physical features, alongside socio-demographics, influence the level of neighbourhood social cohesion, which subsequently affects willingness to engage in acts of social control; or (iii) a concomitant influence of both. Thus, the effectiveness of CE as an explanatory mechanism may be shaped by the ecology of the neighbourhood environment; and this ecology could also shape neighbourhood CE, alongside social and demographic features of settings (Figure 4).

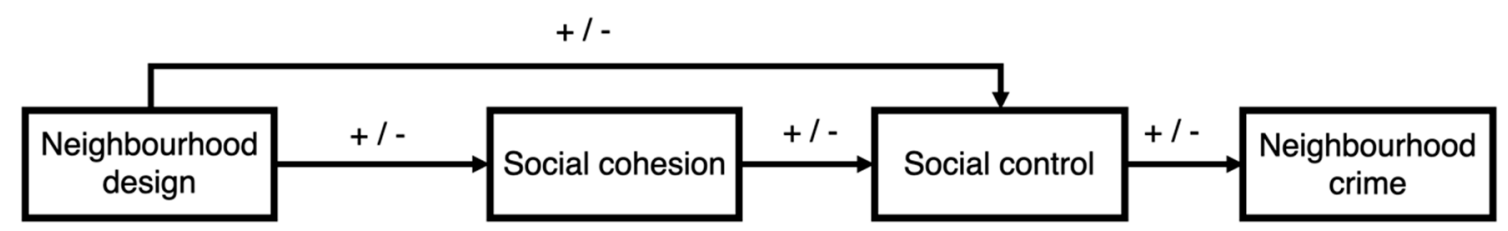

Figure 4. Pathway model illustrating the purported influence of neighbourhood design on CE (social cohesion and social control) and social control directly.

The extent to which a property is overlooked by others has been found to be relevant in explaining property victimisation (Armitage et al. 2010). Breaking this down further, observed measures of resident 'surveillance opportunities', such as an unimpeded view from properties onto the streetscape, have been outlined as one of the most significant predictors of guardianship intensity-that is to say, increased surveillance opportunities permit increased social control within the setting (Reynald 2011a, 2011b).

Whilst such findings lend support to an aspect of the defensible space thesis, CE research shows that the level of social cohesion within the residential setting is also important in shaping the proclivity to engage in social control (see Figure 2). Architects and urban planners moot the benefits of designing, through examples such as the school of 'New Urbanism', neighbourhoods that foster regular interactions as being beneficial to neighbourhood social cohesion (Zelinka and Brennan 2001). Repeated interactions are promoted by CE theory as a means through which communities can come to realise their shared, common values (Sampson 2006, p. 39). Mazumdar et al.'s (2017, p. 5) systematic review found a significant relationship between the walkability of an environment and neighbourhood levels of CE and 'acts of neighbouring'. Findings from the discipline of public health has furthermore identified that the level of street activity in a neighbourhood can come to shape the prevalence of community interactions within a locality, with street layout identified as a physical factor influencing residents' proclivity to be active in community life (Bull et al. 2010, p. 113). This physical focus can further be seen in the number of projects which aim to enhance community cohesion, with built features serving as an anchor point whereby community interactions can be fostered without the need for dense 
social ties (Wickes 2010; Wickes et al. 2018). Resident-centred public land use, such as settings which hosted schools and playgrounds, were articulated as 'social conduits' related to increased measures of 'neighbouring' (Wickes et al. 2018).

\subsubsection{Neighbourhood Design: Limiting Through-Movement}

The built environment may therefore stand to influence $C E$ through design features which enhance shared use of urban space, encouraging social cohesion to resultantly enhance social control. Conversely, spaces which enhance sociality - by being busier, affording communal use-are also evidenced to be conducive to criminality (Brantingham and Brantingham 1993; Taylor 2002) particularly where commercial and residential environments confluence (Weisburd et al. 2012). CPTED promotes limiting the 'through-movement' of people in settings through access control, as a way to (i) restrict offenders' access to neighbourhoods and (ii) encourage resident social control by challenging non-legitimate users of their neighbourhood space (Armitage 2018, p. 264). How urban designs can both limit the access of would-be offenders, whilst also promoting neighbourhood sociality (Armitage and Joyce 2019), is worth consideration when acknowledging CE's role in deterring neighbourhood crime-especially when adaptions to restrict directional movement can be negated through short-cuts (Armitage et al. 2010). Targeted CPTED measures, such as improved streetlighting and the presence of CCTV, have been shown to increase resident activity within the neighbourhood by supressing residents' fear of crime (Lee et al. 2016). One empirical study combining surveys and observations of neighbourhoods in Penang, Malaysia, also found moderate associations between coded observations of CPTED features and measures of neighbourhood CE (Abdullah et al. 2013). Such empirical assessments relating physical features to crime and CE give limited consideration to the social factors which also shape these processes ${ }^{18}$. Whether street design, the CE of the context, or indeed both aspects combined deter would-be offenders has yet to be fully appraised (Figure 5).

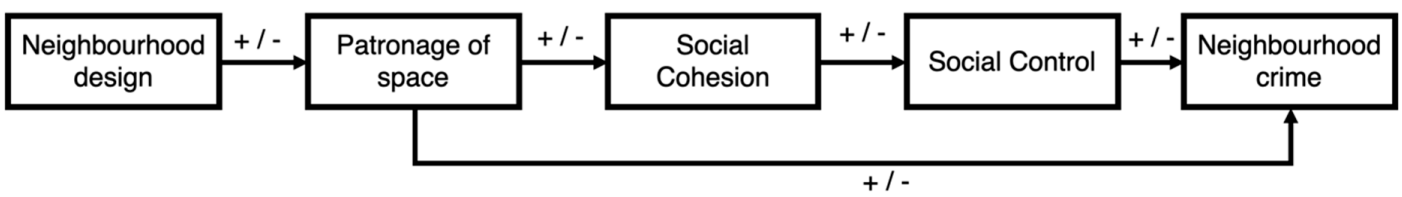

Figure 5. Pathway model illustrating the purported influence of neighbourhood design on the patronage of neighbourhood space, consequently influencing crime directly and through CE.

That said, physical features of place can override the effectiveness of CE as an explanatory deterrent process (Wikström et al. 2012, p. 337). St Jean's (2007) ethnographic work ${ }^{19}$ on the situational dynamics of CE in neighbourhood street blocks, found the effectiveness of CE to be augmented by the type of crime offenders sought to commit, and, in relation to this, the 'ecological advantage' settings conduced to each of these respective crimes. Busier street segments, with many passers-by, were favourable for drug dealing, for dealers were able to avoid suspicion by not being seen to be out of place (St Jean 2007, p. 119). Furthermore, the presence of 'grocery stores, currency exchanges, fast-food restaurants' provided an 'ecological advantage' to robbery, with certain businesses drawing in patronage and potential victims with valuable items in their possession (St Jean 2007, p. 162). Whilst low CE neighbourhoods meant less detection, the features of the setting, and indeed the social selection effects of the neighbourhood, failed to induce victims with valuable personal possessions to make the crime worthwhile (St Jean 2007, p. 162). Conversely, quieter settings—such as parks-were

18 Abdullah et al. (2013) considered the effect of age of respondents in forming CE assessments.

19 Methodologies employed include interviews and surveys with offenders whom often commit or had previously committed different types of crime in the area; interviews and a collective efficacy survey of selected 'neighbourhood experts'; and systematic social observations recorded with a car-mounted video camera with recorded images later coded to consider frequencies of disorder and dilapidated buildings. 
observed to afford young people the ability to offend undetected, within less patronage reducing residents' ability to effectively monitor and control such settings (Wikström et al. 2012, p. 337). In architectural literatures, the affordances within parks have been articulated by young people as a 'retreat', with them able to occupy space 'where no one else really bothers with' (Townshend and Roberts 2013). Thus, the knowledge and experience of ineffective deterrence experiences (see Wikström 2007b; Wikström et al. 2011) can be shaped by physical features minimising the presence of social control from patrons. Not all settings within a measured neighbourhood or unit of aggregation are influenced by such social processes linearly; as criminologists suggest, features of place matter in shaping these responses (Weisburd et al. 2015).

\section{Conclusions}

In this paper, I have argued that in order for neighbourhood effects research to be representative of settings studied, both physical and social features need to be considered alongside each other in explanatory models. By bringing both domains together in an analytical framework, and by using collective efficacy to organise these influences on neighbourhood social processes, researchers will be better able to apportion which features of settings influence responses to the concentration of crime by place. I have argued that the concept of social cohesion is not only important in sustaining neighbourhood crime reductions, but that it can also enhance our understanding of how aspects of CPTED shape individual and neighbourhood-level victimisation-for better or for worse. Integrated empirical study, as I have outlined above, is required in order to apportion these influences, and necessary to break down and operationalise concepts within CPTED and CPTED 2 scholarship. Doing so does not provide us with a holistic account of crime by place-hot spots policing, legal cynicism and procedural legitimacy, and the neighbourhood developmental context to name but a few, are all embroiled in this complex mix. However, it is hoped that integration of CPTED to social processes literatures can help promote empirical enquiry in this regard, benefiting socio-spatial and CPTED scholarship alike.

Funding: This research was funded by an ESRC Studentship, match-funded with Pembroke College, Cambridge (ES/J500033/1).

Conflicts of Interest: The author declares no conflict of interest.

\section{References}

Abdullah, Aldrin, Massoomeh Hedayati Marzbali, and Mohammad Javad Maghsoodi Tilaki. 2013. Predicting the Influence of CPTED on Perceived Neighbourhood Cohesion: Considering Differences across Age. Journal of Environmental Psychology 36: 54-64. [CrossRef]

Armitage, Racheal. 2006. Predicting and Preventing: Developing a Risk Assessment Mechanism for Residential Housing. Crime Prevention and Community Safety: An International Journal 8: 137-49. [CrossRef]

Armitage, Racheal. 2013. Crime Prevention through Environmental Design. In Encyclopedia of Criminology and Criminal Justice. Edited by Gerben Bruinsma and David Weisburd. New York: Springer, pp. 720-31.

Armitage, Racheal. 2018. Crime Prevention through Environmental Design. In Environmental Criminology and Crime Analysis. Edited by Richard Wortley and Michael Townsley. London: Routledge, pp. 259-85.

Armitage, Racheal, and Chris Joyce. 2019. Why my house? Exploring offender perspectives on risk and protective factors in residential housing design. In Rebuilding Crime Prevention Through Environmental Design. Edited by Racheal Armitage and Paul Ekblom. Oxford: Routledge.

Armitage, Racheal, and Leanne Monchuk. 2011. Sustaining the Crime Reduction Impact of Secured by Design: 1999 to 2009. Security Journal 24: 320-43. [CrossRef]

Armitage, Racheal, Leanne Monchuk, and Michelle Rogerson. 2010. It Looks Good, But What is it Like to Live There? Assessing the Impact of Award Winning Design on Crime. Special Volume of European Journal of Criminal Policy and Research 17: 29-54. [CrossRef]

Baldwin, John, Anthony E. Bottoms, and Monica A. Walker. 1976. The Urban Criminal: A study in Sheffield. London: Tavistock Publications. 
Bernasco, Wim. 2010. A Sentimental Journey to Crime: Effects of Residential History on Crime Location Choice. Criminology 48: 389-416. [CrossRef]

Bottoms, Anthony. 1974. Reviews. Defensible Space by Oscar Newman. The British Journal of Criminology 14: 203-6. [CrossRef]

Bottoms, Anthony E. 1990. Crime Prevention Facing the 1990s. Policing and Society 1. [CrossRef]

Bottoms, Anthony. 2012. Developing Socio-Spatial Criminology. In The Oxford Handbook of Criminology, 5th ed. Edited by Mike Maguire, Rod Morgan and Robert Reiner. Oxford: Oxford University Press, pp. 450-89.

Bottoms, Anthony. 2017. Crime Specifics, Offender Residences, and Social Change: Developing the Criminology of Place. Jerusalem Review of Legal Studies 15: 1-11. [CrossRef]

Brantingham, Patricia L., and Paul J. Brantingham. 1981. Notes on the Geometry of Crime. In Environmental Criminology. Edited by Paul Brantingham and Patricia Brantingham. London: SAGE, pp. 7-54.

Brantingham, Paul J., and Patricia L. Brantingham. 1993. Environment, Routine and Situation: Toward a Pattern Theory of Crime. In Routine Activity and Rational Choice. Edited by Ronald V. Clarke and Marcus Felson. New Brunswick: Transaction Publications, pp. 259-94.

Brantingham, Paul J., Patricia L. Brantingham, and Martin A. Andresen. 2018. The Geometry of Crime and Crime Pattern Theory. In Environmental Criminology and Crime Analysis, 2nd ed. London: Routledge.

Browning, Christopher R. 2002. The Span of Collective Efficacy: Extending Social Disorganization Theory to Partner Violence. Journal of Marriage and Family 64: 833-50. [CrossRef]

Browning, Christopher R., Seth L. Feinberg, and Robert D. Dietz. 2004. The Paradox of Social Organization: Networks, Collective Efficacy, and Violent Crime in Urban Neighbourhoods. Social Forces 83: 503-34. [CrossRef]

Brunton-Smith, Ian, Alex Sutherland, and Jonathan Jackson. 2013. The Role of Neighbourhoods in Shaping Crime and Perceptions of Crime. In Neighbourhood Effects or Neighbourhood Based Problems? Edited by David Manley, Maarten van Ham, Nick Bailey, Ludi Simpson and Duncan Maclennan. London: Springer.

Brunton-Smith, Ian, Patrick Sturgis, and George Leckie. 2018. How Collective is Collective Efficacy? The Importance of Consensus in Judgements about Community Cohesion and Willingness to Intervene. Criminology 56: 608-37. [CrossRef]

Bull, Fiona, Billie Giles-Corti, and Lisa Wood. 2010. 'Active landscapes: The methodological challenges in developing the evidence on urban environments and physical activity'. In Innovative Approaches to Researching Landscape in Health. Open Space: People Space 2. Edited by Catharine Ward Thompson, Peter Aspinall and Simon Bell. London: Routledge, pp. 99-121.

Bursik, Bob J. 2015. Social Sources of Delinquency and the Second Coming of Shaw and McKay. In Challenging Criminological Theory. The Legacy of Ruth Rosner Kornhauser. Edited by Francis T. Cullen, Pamela Wilcox, Robert J. Sampson and Brendan D. Dooley. Piscataway: Transaction Publishers.

Coleman, Alice. 1989. Disposition and Situation: Two Sides of the Same Crime. In The Geography of Place. Edited by David J. Evans and David T. Herbert. London: Routledge.

Coleman, Alice, Brown Sarah, Cottle Lise, Marshall Pauline, Redknap Celia, and Sex Rachel. 1990. Utopia on Trial: Vision and Reality in Planned Housing. London: Hillary Shipman.

Colquhoun, Ian. 2004. Design Out Crime: Creating Safe and Sustainable Communities. London: Elsevier.

Cornish, Derek B., and Ronald V. Clarke. 2003. Opportunities, Precipitators and Criminal Decisions: A Reply to Wortley's Critique of Situational Crime Prevention. Crime Prevention Studies 16: 41-96.

Cozens, Paul, and Tom Davies. 2013. Investigating 'Eyes on the Street', Perceptions of Crime and the use of Security Shutters-Insights from a Residential Suburb in Perth (WA). Crime Prevention and Community Safety 15: 175-91. [CrossRef]

Cozens, Paul, and Terence Love. 2015. A Review and Current Status of Crime Prevention through Environmental Design. Journal of Planning Literature 30: 393-412. [CrossRef]

Cozens, Paul M., Greg Saville, and David Hillier. 2005. Crime prevention through environmental design (CPTED): A review and modern bibliography. Property Management 23: 328-56. [CrossRef]

Duncan, Terry E., Susan C. Duncan, Hayrettin Okut, Lisa A. Strycker, and Hollie Hix-Small. 2003. A Multilevel Contextual Model of Neighborhood Collective Efficacy. American Journal of Community Psychology 32: 245-52. [CrossRef]

Ekblom, Paul. 2011. Guest Editor's Introduction. European Journal on Criminal Policy and Research 17: 1-5. [CrossRef] 
Ekblom, Paul. 2019. Sharpening up CPTED—Towards and Ontology Based on Crime Science and Ecology. In Rebuilding Crime Prevention Through Environmental Design. Edited by Racheal Armitage and Paul Ekblom. Abingdon: Routledge.

Farrell, Graham, Nick Tilley, and Andromachi Tseloni. 2014. Why the Crime Drop? In Crime and Justice. Edited by Michael Tonry. Chicago: University of Chicago Press, vol. 43, pp. 421-90.

Fennelly, Lawrence, and Crowe Timothy. 2013. Crime Prevention through Environmental Design, 3rd ed. Oxford: Butterworth-Heinemann.

Garland, David. 2002. The Culture of Control. Oxford: Oxford University Press.

Hillier, Bill, and Simon Shu. 2000. Crime and urban layout: The need for evidence. In Secure Foundations. Key Issues in Crime Prevention, Crime Reduction, and Community Safety. Edited by Scott Ballintyne, Ken Pease and Vic McLaren. Southampton: Institute for Public Policy Research, pp. 224-48.

Hipp, John R., Seth A. Williams, and Adam Boessen. 2018. Disagreement in Assessing Neighboring and Collective Efficacy: The Role of Social Distance. Sociological Research for a Dynamic World 4: 1-16. [CrossRef]

Hollis-Peel, Meghan, Danielle Reynald, and Brandon C. Welsh. 2012. Guardianship and Crime: An International Comparative Study of Guardianship in Action. Crime, Law and Social Change 58: 1-14. [CrossRef]

Home Office. 2016. Reducing Criminal Opportunity: Vehicle Security and Vehicle Crime; Research Report 87. Available online: https://assets.publishing.service.gov.uk/government/uploads/system/uploads/attachment_data/file/ 489097/horr87.pdf (accessed on 9 May 2019).

Hope, Tim, and Susanne Karstedt. 2003. Towards a New Social Crime Prevention. In Crime Prevention: New Approaches. Edited by Helmut Kury and Joachim Obergfell-Fuchs. Mainz: Weisser Ring.

Innes, Martin. 2004. Signal Crimes and Signal Disorders: Notes on Deviance as Communicative Action. British Journal of Sociology 55: 335-55. [CrossRef]

Jacobs, Jane. 1961. The Death and Life of Great American Cities. New York: Random House.

Jeffery, C Ray. 1971. Crime Prevention through Environmental Design. Los Angeles: Sage.

Jephcott, Pearl. 1971. Homes in High Flats: Some of the Human Problems Involved in Multi-Storey Housing. Edinburgh: Oliver \& Boyd.

Johnson, Shane, and Kate Bowers. 2010. Permeability and Burglary Risk: Are Cul-de-Sacs Safer? Quantitative Journal of Criminology 26: 89-111. [CrossRef]

Kornhauser, Ruth. 1978. Social sources of Delinquency. An Appraisal of Analytical Models. Chicago: University of Chicago Press.

Lee, Jae S., Sungjin Park, and Sanghoon Jung. 2016. Effect of Crime Prevention through Environmental Design (CPTED) Measures on Active Living and Fear of Crime. Sustainability 8: 872. [CrossRef]

Maimon, David, and Christopher R. Browning. 2010. Unstructured Socializing, Collective Efficacy, and Violent Behavior among Urban Youth. Criminology 48: 443-74. [CrossRef]

Mazerolle, Lorraine, Rebecca Wickes, and James McBroom. 2010. Community Variations in Violence: The Role of Social Ties and Collective Efficacy in Comparative Context. Journal of Research in Crime and Delinquency 47: 3-30. [CrossRef]

Mazumdar, Soumya, Vincent Learnihan, Thomas Cochrane, and Rachel Davey. 2017. The Built Environment and Social Capital: A Systematic Review. Environment and Behavior 50: 1-40. [CrossRef]

Merry, Sally E. 1981. Defensible Space Undefended. Social Factors in Crime Control through Environmental Design. Urban Affairs Quarterly 16: 397-422. [CrossRef]

Miethe, Terance D., and Robert F. Meier. 1990. Opportunity, Choice, and Criminal Victimization: A Test of a Theoretical Mode. Journal of Research in Crime and Delinquency 27: 243-66. [CrossRef]

Minnery, John R., and Bill Lim. 2005. Measuring Crime Prevention through Environmental Design. Journal of Architectural and Planning Research 22: 330-41.

Montoya, Lorena, Marianne Junger, and Yfke Ongena. 2016. The Relation between Residential Property and its Surrounding and Day- and Night-Time Residential Burglary. Environment and Behaviour 48: 515-49. [CrossRef]

Morenoff, Jeffrey D., Robert J. Sampson, and Stephen W. Raudenbush. 2001. Neighborhood Inequality, Collective Efficacy, and the Spatial Dynamics of Urban Violence. Criminology 39: 517-60. [CrossRef]

Nee, Claire, and Max Taylor. 2000. Examining Burglars' Target Selection: Interview, Experiment or Ethnomethodology? Psychology, Crime \& Law 6: 45-59.

Newman, Oscar. 1972. Defensible Space. London: Architectural Press. 
Newman, Oscar. 1976. Design Guidelines for Creating Defensible Space. Washington: National Institute of Law Enforcement and Criminal Justice.

Newman, Oscar. 1980. Community of Interest. New York: Doubleday.

Oberwittler, Dietrich, and Per-Olof H. Wikström. 2009. Why Small Is Better: Advancing the Study of the Role of Behavioural Contexts in Crime Causation. In Putting Crime in its Place. Edited by David Weisburd, Wim Bernasco and Gerben J. N. Bruinsma. New York: Springer, pp. 35-60.

Odgers, Candice L., Avshalom Caspi, Christopher J. Bates, and Robert J. Sampson. 2012. Systematic social observation of children's neighborhoods using Google Street View: A reliable and cost-effective method. Journal of Child Psychology and Psychiatry 53: 1009-17. [CrossRef]

Park, Robert E., Ernest W. Burgess, and Roderick D. McKenzie. 1925. The City. Chicago: University of Chicago Press.

Raudenbush, Stephen W., and Robert J. Sampson. 1999. Ecometrics: Toward A Science of Assessing Ecological Settings, with Application to the Systematic Social Observation of Neighborhoods. Sociological Methodology 29: 1-41. [CrossRef]

Reynald, Danielle M. 2009. Guardianship in Action: Developing a new tool for Measurement. Crime Prevention and Community Safety: An International Journal 11: 1-20. [CrossRef]

Reynald, Danielle M. 2010. Guardians on Guardianship: Factors Affecting the Willingness to Monitor, the Ability to Detect Potential Offenders \& the Willingness to Intervene. Journal of Research in Crime and Delinquency 47: 358-90.

Reynald, Danielle M. 2011a. Translating CPTED into Crime Preventative Action: A Critical Examination of CPTED as a Tool for Active Guardianship. European Journal on Criminal Policy and Research 17: 69-81. [CrossRef]

Reynald, Danielle M. 2011b. Factors Associated with the Guardianship of Places: Assessing the Relative Importance of the Spatio-Physical and Sociodemographic Contexts in Generating Opportunities for Capable Guardianship. Journal of Research in Crime and Delinquency 48: 110-42. [CrossRef]

Reynald, Danielle M., and Mateja Mihinjac. 2019. Using Guardianship and Situational Crime Prevention (SCP) to Strengthen Crime Prevention through Environmental Design (CPTED). In Rebuilding Crime Prevention Through Environmental Design. Edited by Racheal Armitage and Paul Ekblom. Abingdon: Routledge.

Rosenau, Helen. 1959. The Ideal City: Its Architectural Evolution in Europe. London: Routledge.

Sampson, Robert J. 2004. Neighborhood and community: Collective efficacy and community safety. New Economy 11: 106-13. [CrossRef]

Sampson, Robert J. 2006. How does community context matter? Social mechanisms and the explanation of crime rates. In The Explanation of Crime. Edited by Per-Olof H. Wikström and Robert J. Sampson. Cambridge: Cambridge University Press, pp. 31-60.

Sampson, Robert J. 2008. Collective Efficacy Theory: Lessons Learned and Directions for Future Inquiry. In Taking Stock: The Status of Criminological Theory. Edited by Francis T. Cullen, John Paul Wright and Kristie R. Blevins. London: Transaction Publishers, pp. 149-64.

Sampson, Robert J. 2012. Great American City. Chicago and the Enduring Neighbourhood Effect. Chicago: University of Chicago Press.

Sampson, Robert J. 2016. Urban sustainability in an age of enduring inequalities: Advancing theory and ecometrics for the 21st-century city. Proceedings of the National Academy of Sciences 114: 8957-62. Available online: www.pnas.org/cgi/doi/10.1073/pnas.1614433114 (accessed on 9 May 2019). [CrossRef]

Sampson, Robert J., and Jeffrey D. Morenoff. 2004. Spatial (Dis)Advantage and Homicide in Chicago Neighborhoods. In Spatially Integrated Social Science. Edited by Michael Goodchild and Donald Janelle. Oxford: Oxford University Press, pp. 145-70.

Sampson, Robert J., and Stephen W. Raudenbush. 2001. Disorder in Urban Neighbourhoods—Does It Lead To Crime? National Institute of Justice Research in Brief, February.

Sampson, Robert J., and Per-Olof H. Wikström. 2008. The social order of violence in Chicago and Stockholm neighborhoods: A comparative inquiry. In Order, Conflict, and Violence. Edited by Stathis N. Kalyvas, Ian Shapiro and Tarek Masoud. Cambridge: Cambridge University Press, pp. 97-119.

Sampson, Robert J., Stephen W. Raudenbush, and Felton Earls. 1997. Neighborhoods and Violent Crime: A Multilevel Study of Collective Efficacy. Science 277: 918-24. [CrossRef]

Sampson, Robert J., Jeffrey D. Morenoff, and Felton Earls. 1999. Beyond Social Capital: Spatial Dynamics of Collective Efficacy for Children. American Sociological Review 64: 633-60. [CrossRef] 
Sampson, Robert J., Jeffrey D. Morenoff, and Thomas Gannon-Rowley. 2002. Assessing “Neighborhood Effects": Social Processes and New Directions in Research. Annual Review of Sociology 28: 443-78. [CrossRef]

Saville, Gregory, and Gerard Cleveland. 2008. Second-Generation CPTED: The Rise and Fall of Opportunity Theory. In 21st Century Security and CPTED: Designing for Critical Infrastructure Protection and Crime Prevention. Edited by Randall Atlas. Boca Raton: Auerbach Publications, pp. 79-90.

Secured By Design. 2014. The Safer Tram Stop Award. Available online: https://www.securedbydesign.com/ images/downloads/The-Safer-Tram-Award-Guidence.pdf (accessed on 9 May 2019).

Secured By Design. 2015. Commercial Developments 2015. Available online: https://www.securedbydesign.com/ images/downloads/SBD_Commercial_2015_V2.pdf (accessed on 9 May 2019).

Secured By Design. 2019. Homes 2019. Available online: https://www.securedbydesign.com/images/downloads/ HOMES_BROCHURE_2019.pdf (accessed on 9 May 2019).

Sennett, Richard. 1996. The Uses of Disorder. Personal Identity and City Life. London: Faber and Faber.

Sherman, Lawrence W., Patrick R. Gartin, and Michael E. Buerger. 1989. Hot Spots of Predatory Crime: Routine Activities and the Criminology of Place. Criminology 27: 27-56. [CrossRef]

St Jean, Peter K.B. 2007. Pockets of Crime: Broken Windows, Collective Efficacy, and the Criminal Point of View. Chicago: University of Chicago Press.

Steenbeek, Wouter, and John R. Hipp. 2011. A longitudinal test of social disorganization theory: Feedback effects among cohesion, social control and disorder. Criminology 49: 833-71. [CrossRef]

Sutherland, Alex, Ian Brunton-Smith, and Jonathan Jackson. 2013. Collective Efficacy, Deprivation and Violence in London. British Journal of Criminology 53: 1050-74. [CrossRef]

Taylor, Ralph B. 2002. Crime Prevention through Environmental Design (CPTED): Yes, No, Maybe, Unknowable, and All of the Above. In Handbook of Environmental Psychology. Edited by Robert B. Bechtel and Arza Churchman. New York: Wiley, pp. 413-25.

Taylor, Ralph B. 2015. Community Criminology. Fundamentals of Spatial and Temporal Scaling, Ecological Indicators, and Selectivity Bias. New York: NYU Press.

Tilley, Nick, Rebecca Thompson, Graham Farrell, Louise Grove, and Andromachi Tseloni. 2015. Do burglar alarms increase burglary risk? A counter-intuitive finding and possible explanations. Crime Prevention and Community Safety 17: 1-19. [CrossRef]

Townshend, Tim G., and Marion Roberts. 2013. Affordances, Young People, Parks and Alcohol Consumption. Journal of Urban Design 18: 494-516. [CrossRef]

Tseloni, Andromachi, Karin Wittebrood, Graham Farrell, and Ken Pease. 2004. Burglary Victimization in England and Wales, the United States and the Netherlands. British Journal of Criminology 44: 66-91. [CrossRef]

Tseloni, Andromachi, Rebecca Thompson, Louise E. Grove, Nick Tilley, and Graham Farrell. 2017. The Effectiveness of Burglary Security Devices. Security Journal 30: 646-44. [CrossRef]

Tuffrey, Peter. 2013. Sheffield Flats: Park Hill and Hyde Park. Stroud: Fonthill Media.

Vandeviver, Christophe. 2014. Applying Google Maps and Google Street View in criminological research. Crime Science 3. [CrossRef]

Volker, Beate, Gerald Mollenhorst, Wouter Steenbeek, Veronique Schutjens, and Henk Flap. 2016. Lost Letters in Dutch Neighborhoods: A Field Experiment on Collective Efficacy. Social Forces 94: 953-74. [CrossRef]

Vollaard, Ben, and Jan C. van Ours. 2011. Does Regulation of Built-in Security Reduce Crime? Evidence form a Natural Experiment. The Economic Journal 121: 485-504. [CrossRef]

Weisburd, David, Elizabeth R. Groff, and Sue-Ming Yang. 2012. The Criminology of Place. Oxford: Oxford University Press.

Weisburd, David, Michael Davis, and Charlotte Gill. 2015. Increasing Collective Efficacy and Social Capital at Crime Hot Spots: New Crime Control Tools for Police. Policing: A Journal of Policy and Practice 9: 265-74. [CrossRef]

Welsh, Brandon C., and David P. Farrington. 2009. Making Public Spaces Safer: Surveillance and Crime Prevention. Oxford: Oxford University Press.

West Midlands Police and Crime Commissioner. 2018. Car Thefts Nearly Triple. Available online: https: //www.westmidlands-pcc.gov.uk/news/news-2018/car-thefts-nearly-triple/ (accessed on 20 March 2019).

Wickes, Rebecca L. 2010. Generating Action and Responding to Local Issues: Collective Efficacy in Context. The Australian and New Zealand Journal of Criminology 43: 423-43. [CrossRef] 
Wickes, Rebecca, Renee Zahnow, Jonathan Corcoran, and John R. Hipp. 2018. Neighbourhood Social Conduits and Resident Social Cohesion. Urban Studies 56: 226-48. [CrossRef]

Wikström, Per-Olof H. 1991. Urban Crime, Criminals and Victims: The Swedish Experience in an Anglo-American Comparative Perspective. Berlin: Springer.

Wikström, Per-Olof H. 2006. Individuals, settings, and acts of crime: Situational mechanisms and the explanation of crime. In The Explanation of Crime. Context, Mechanisms, and Development. Edited by Per-Olof H. Wikström and Robert J Sampson. Cambridge: Cambridge University Press, pp. 61-107.

Wikström, Per-Olof H. 2007a. The social ecology of crime: The role of the environment in crime causation. In Internationales Handbuch der Kriminologie. Edited by Hans J. Schneider. Berlin: De Gruyter, pp. 333-57.

Wikström, Per-Olof H. 2007b. Deterrence and Deterrence Experiences: Preventing Crime through the Threat of Punishment. In International Handbook of Penology and Criminal Justice. Edited by Shlomo G. Shoham, Ori Beck and Martin Kett. Eastbourne: Sussex Academic Press.

Wikström, Per-Olof H. 2011. Social Sources of Crime Propensity. A Study of the Collective Efficacy of the Family, the School and the Neighbourhood. In Antisocial Behavior and Crime: Contributions of Theory and Evaluation Research to Prevention and Intervention. Edited by Thomas Bliesener, Andreas Beelmann and Mark Stemmler. Goettingen: Hogrefe, pp. 109-22.

Wikström, Per-Olof H. 2017. Character, circumstances, and the causes of crime: Towards an analytical criminology. In The Oxford Handbook of Criminology, 6th ed. Edited by Alison Liebling, Shadd Maruna and Lesley McAra. Oxford: Oxford University Press.

Wikström, Per-Olof H., and Robert J. Sampson. 2003. Social Mechanisms of Community Influences on Crime and Pathways in Criminality. In Causes of Conduct Disorder and Juvenile Delinquency. Edited by Benjamin B. Lahey, Terrie E. Moffit and Avshalom Caspi. London: The Guildford Press, pp. 118-48.

Wikström, Per-Olof H., and Kyle Treiber. 2017a. Beyond Risk Factors: An Analytical Approach to Crime Prevention. In Preventing Crime and Violence, Advances in Prevention Science. Edited by Brent Teasdale and Mindy Bradley. New York: Springer, vol. 2, pp. 73-90.

Wikström, Per-Olof H., Tseloni Andromachi, and Dimitris Karlis. 2011. Do people comply with the law because they fear getting caught? European Journal of Criminology 8: 401-20. [CrossRef]

Wikström, Per-Olof H., Dietrich Oberwittler, Kyle Treiber, and Beth Hardie. 2012. Breaking Rules: The Social and Situational Dynamics of Young People's Urban Crime. Oxford: Oxford University Press.

Wilcox, Pamela, Neil Quisenberry, and Shayne Jones. 2003. The Built Environment and Community Crime Risk and Interpretation. Journal of Research in Crime and Delinquency 40: 322-45. [CrossRef]

Wilcox, Pamela, Tamara D. Madensen, and Marie S. Tillyer. 2007. Guardianship in Context: Implications for Burglary Victimization Risk and Prevention. Criminology 45: 771-803. [CrossRef]

Wilcox, Pamela, Francis T. Cullen, and Ben Feldmeyer. 2018. Communities and Crime. An Enduring American Challenge. Philadelphia: Temple University Press.

Wortley, Richard, and Nick Tilley. 2018. Does situational crime prevention require a rational offender? In The Future of Rational Choice for Crime Prevention. Edited by Danielle M. Reynald and Benoit Leclerc. London: Routledge, pp. 8-27.

Zelinka, Al, and Dean Brennan. 2001. Safescape: Creating Safer More Livable Communities through Planning and Design. Chicago: American Planning Association.

(C) 2019 by the author. Licensee MDPI, Basel, Switzerland. This article is an open access article distributed under the terms and conditions of the Creative Commons Attribution (CC BY) license (http://creativecommons.org/licenses/by/4.0/). 